\title{
Investigating the Mediation Role of Information Technology (IT) Components in the Relationship between Knowledge Management (KM) Processes and Decision-Making
}

\author{
Maha Alkhaffaf ${ }^{1}$ \\ ${ }^{1}$ Management Information Systems Department, The World Islamic Sciences and Education University, Jordan \\ Correspondence: Maha Alkhaffaf, Management Information Systems Department, The World Islamic Sciences \\ and Education University, Jordan. E-mail: alkhaffaf@yahoo.com
}

Received: January 26, 2018

doi:10.5539/ijbm.v13n4p108

\author{
Accepted: February 27, 2018 \\ Online Published: March 18, 2018 \\ URL: https://doi.org/10.5539/ijbm.v13n4p108
}

\begin{abstract}
This paper is focused on providing a justification and rationale for the relationship between Knowledge Management (KM) theories, components of Information Technology (IT), and Decision-Making. A literature review is provided with the aim of examining the potential constructs associated with KM processes and components of IT in order to investigate potential aspects and factors pertaining to Decision-Making. In consideration to the findings garnered through the literature review, a research hypothetical framework was devised, combining the model characteristic constructs of the suggested model. In order to achieve framework validation, a survey was carried out across a total of 182 technical and administrative staff employed by various top and middle levels at a telecommunications organisation in Jordan-notably, Zain. Through the application of PLS Graph software coupled with the Structural Equation Model (SEM), an analysis was completed in consideration to the interrelationships inherent in those latent variables identified, comprising Decision-Making, IT components and KM processes. The findings garnered following the completion of the analysis suggest that there is an entirely mediating role in Knowledge Discovery and Knowledge Update. Furthermore, Knowledge-Sharing and Knowledge Application are, in part, mediating. In contrast, however, the relationship between IT components and Decision-Making are not mediated by Knowledge Capture and Knowledge Storage.

This paper has been successful in filling the gap in the literature through garnering and highlighting further empirical evidence pertaining to the effects of KM processes on Decision-Making, with IT components positioned as a mediation construct.
\end{abstract}

Keywords: Knowledge Management, Knowledge Management (KM) processes, Information Technology (IT), Decision-Making

\section{Introduction}

Owing to the significant development and advances being made in the IT arena in terms of change and progress, Knowledge Management (KM) processes have become recognised as pivotal when it comes to devising and maintaining an effective and efficient link with Decision-Making. Furthermore, a significant number of decision-making strategies have been introduced, although these depend on the structure of information available. Importantly, in the modern-day world, which is more competitive than ever before, productivity, as an overall philosophical concept, centred on improved Decision-Making in this context, shapes one of the most fundamental objectives of any firm; therefore, KM processes have quickly become identified, and accordingly positioned, as one of the main priorities amongst IT professionals. Due to this recognition stemming back several years, the market has also introduced a number of related software products, which, in turn, has facilitated and further spurred on growth in this arena, irrespective of the challenging environmental conditions (Alhawari. S. et al, 2012) Moreover, it is acknowledged that, in today's complicated environment, decision-making has necessitated efficient operation under conditions of uncertainty and rapid change; this has warranted training and teaching in meta-cognitive skills, which provide leaders and executives with decision-making choices when faced with new, challenging situations (Fornell \& Larcker, 1981)

In more recent times, the value and importance of information and knowledge in influencing and shaping the various roles of innovation and technological development, as well as the changes facilitating the 
competitiveness and continuous change of organisations in the way in which people are connected and interact in knowledge-sharing and exchange, has been afforded attention in the work of Pereira and Quoniam (2017). The work recognised the potential associated with ensuring access to opportunities and expanding abilities, with competitive advantage and economic growth identified as possible valuable outcomes in this regard. Furthermore, the study carried out by Janssen et al. (2017) identifies Information and Computer Technology (ICT) as demonstrating significant, rapid change, meaning society, in turn, is coming to increase their demands and expectations, seeking out higher quality information to underpin any decision-making. As has been highlighted in the work by Capalbo et al. (2017), the study of organisations have outlined a wealth of knowledge and institutional arrangements which, when combined, create a structure providing agricultural landscapes management with support through site-focused knowledge. This, in turn, is used in combination with analytical instruments in an effort to enhance decision-making quality across firms.

In a research carried out recently, the way in which knowledge use can be influenced in supporting decision-making was analysed by Horita et al. (2017). In line with the development of large volumes of data and new data sources, one of the obstacles facing businesses in the modern-day world is that of establishing how decision-making and organisational processes can be aligned with knowledge in such a way so as to help establish better informed decisions. Irrespective of the validation and confirmation provided by the researcher in regards the advantages of knowledge, it has been emphasised by Piechnicki et al. (2017) that the knowledge base needing to be established becomes more consistent and dependable, as well as stronger, thereby enhancing decision-making credibility through the adoption of techniques centred on enhanced knowledge quality and consistency. In this regard, IT and KM are seen to have developed in such a way to have become a fundamental aspect of businesses. In a similar vein, it has been noted by Santos et al. (2017) that knowledge needs to be directed towards the system and process integration, with the inclusion of decision-making processes focused on enhancing and improving knowledge processes so as to highlight how decision-making process and conciliation can occur through conceptual maps, focusing on identifying the knowledge involved.

In consideration to all of the above, this work seeks to outline a number of particular and fundamental points, all of which are intended to provide contributions to developing greater insight into and understanding of the KM process, with the objective to enhance decision-making through IT component utilisation. Otherwise stated, the theory linked with $\mathrm{KM}$ and decision-making not only fails to encompass processes focused on evaluating decision-making maturity from the perspective of KM processes, but also lacks in terms of addressing IT components at different levels of decision-making. Furthermore, very little academic research has focused on other aspects, including examining the mediatory role adopted by components of IT in the link between KM and Decision-Making. Accordingly, the present literature lacks in this regard, specifically in the organisational context. As a result, in order to garner a more in-depth insight into the way in which IT components and KM influence the role and overall competences of Decision-Making, this study was carried out with the hope of filling this gap in the literature. A framework will be suggested to highlight various processes associated with $\mathrm{KM}$, rationalising and explaining the role of IT in analysing development, the degree of such, and accordingly suggesting the fundamentals required in order to enhance organisational Decision-Making.

The remainder of this paper is broken down as follows: Section 2 provides an overview of other works pertinent to the literature review, in addition to various valuable definitions concerning the key themes of this study, associated with Decision-Making, KM and IT components; Section 3 introduces the conceptual framework, which explains the link between constructs, in addition to the research hypothesis with the aim of describing the mediatory role adopted by IT components in the link between KM processes and Decision-Making; Section 4 presents a discussion centred on data analysis and results; and lastly, Section 5 draws conclusions and makes recommendations for future works.

\section{Literature Review}

\subsection{Knowledge Management Concept}

Understanding relating to the concept of KM differs in line with the various perspectives on which researchers seek to focus in applications. The KM concept was presented and subsequently developed by Nonaka in the 1990s, predominantly with focus on the knowledge-transfer process, and the adoption of such, as explained by two different forms of knowledge, namely tacit and explicit. Importantly, this concept continues to be recognised as a critical foundation underpinning this discipline, and is adopted in mind of enhance organisational policy. (Marinagi et al., 2014)

The work of Alharithy (2015) acknowledged the perspective of modern technology in line with knowledge management application in providing new tools and capacities, special competitive abilities, and the 
wide-ranging adoption of IT and management. It further outlines an effective and accurate system with the potential to draw, apply and oversee a number of different functional processes, support the philosophy and perspectives of high administration, and shape and influence individuals' attitudes, abilities, behaviours and capacities within the firm. More recently, knowledge management has been considered by Torabi \& El-Den (2017) as positioned to establish a suitable construction and critical technological infrastructure in businesses that highlight the foundation of policy through the correct knowledge, in the correct form and for the correct audience.

Other scholars in this field, including Said et al. (2014), consider KM as an essential activity warranting attention and effective application by businesses, and has been acknowledged as a critical aspect in ensuring the success of any firm. In this vein, KM has been defined by Dalmarco et al. (2017) as the sequences of process that generate, share, distribute and use knowledge in the organisation. Furthermore, KM, as a concept, has been defined by Merlo (2016) as encompassing those processes of capturing, distributing and utilising, and is seen to be central in regards the effective operation of KM strategies in achieving results in what is a competitive business world. Comparably, the concept of KM has been clarified by El Said (2015) as commonly placing the most importance on the strategic objectives of the firm, whether in terms of competitive advantage, enhanced performance or innovation, with a notable role played by this concept in enhance individual and business performance.

\subsection{Knowledge Management Processes Model}

A number of KM processes have been identified in various existing process frameworks in the KM arena, with Abubakar et al. (2017), for example, recently breaking KM down into a comprehensive theoretical model associated with Decision-Making. This model comprises six individual steps: first, Knowledge-Creation, which centres on creating new knowledge that may be valuable to the firm; Knowledge Capture is focused on the creation of new content whilst replacing existing knowledge; Knowledge Organisation focuses on the sharing of knowledge whilst also considering knowledge structure listing and modelling; Knowledge Storage relates to the storage and retrieval of knowledge whenever necessary; Knowledge Dissemination directs attention to knowledge-transfer, whether from one individual to the next, or otherwise across a firm or group, adopting various approaches in this regard; and lastly, Knowledge Application aims to implement knowledge action, overcome knowledge-related problems, and aid Decision-Making, which can lead to the creation of new knowledge.

One further interesting theory of $\mathrm{KM}$, relevant when considering channelling knowledge, is presented in the work of Moreno \& Cavazotte (2015). This particular cycle comprises three processes through which firms are positioned to adapt KM, namely knowledge acquisition, sharing and leverage-with all processes geared towards satisfying business objective through positioning and enabling members of the business to collectively deal with KM factors. The model introduced by Lai and Lin (2012) in the KM process arena is broken down into three individual stages, in line with KM mechanisms and their content and nature. The three dynamic processes are identified as the creation and acquisition of knowledge, the diffusion and integration of knowledge, and the storage of knowledge.

In another research completed by Cerchione and Esposito (2017), the extent to which KM diffusion and use intensity processes can be identified in organisations, in line with IT system adoption in order to support the three KM processes. Primarily, IT tools support the phase of knowledge creation through the implementation of Data Mining and Data Visualisation strategies. Secondarily, knowledge storage is further aided by IT tools, in line with Business Process Management Systems. And lastly, the knowledge transfer process is supported by IT tools in the application and utilisation of Cloud Computing and other LMSs (Learning Management Systems).

$\mathrm{KM}$ and technology are recognised as playing a combined and critical role in organisational success, therefore positioning KM as critical (Allameh et al., 2011). The KM cycle can be broken down into six different processes, including knowledge creation, capture, organisation, storage, distribution, and application.

Furthermore, four different processes of KM-all of which are linked with ICT in the pursuit of satisfying business performance - have been recognised by Kiatsuranon \& Suwunnamek (2017) as a part of an organisation. These processes included the creation and acquisition of knowledge, the storage of knowledge, the transfer of knowledge, and the application of knowledge. Moreover, in this same vein, Tubigi and Alshawi (2012) made reference to the lifecycle of KM processes as comprising creation and acquisition, modification, use, transfer, archiving, translating, access, and disposal. In addition, the KM process dimensions are recognised by Ahani et al. (2013) as encompassing knowledge identification, knowledge acquisition, knowledge selection, knowledge storage, knowledge distribution, knowledge creation, knowledge application, and knowledge business. 


\subsection{The Advantage of Knowledge Management Processes across Firms}

Businesses face a number of challenges; however, when seeking to achieve a competitive edge, one of the challenges experienced pertains to enhancing decision-making. Accordingly, KM processes and corresponding technology has been highlighted in the work of Lai and Lin (2012) as becoming the focus of increasing measurement as one aspect of strategic asset and as the main source of achieving a competitive advantage, with the scholars recognising that technological innovation, new product development performance and KM process application can be pivotal in securing new knowledge, which ultimately enhances innovative activity performance (Alhawari \& Aljarrah, 2012)

It is recognised by Dalmarco et al. (2017) that, in order to be competitive in the present knowledge economy, new firms need to consider the importance of efficiently using KM so as to implement development strategies. As a result, there is a pressing need to recognise and acknowledge the value of KM processes. Similarly, the work of Sallan et al. (2012) suggests the same, highlighting KM is an asset with significant strategic value, with businesses, as a result, finding themselves focused on identifying new strategies that will enable their members to create and share knowledge through new ICT-based tools. It is considered that this approach could be pivotal in encouraging more valuable collaboration, facilitating different types of collaborative work. In this regard, the continuous growth and success witnessed in businesses has been outlined by Allameh et al. (2011) as owing to the use of IT with knowledge, which has positioned firms to shift their attention towards adopting economical approaches based on knowledge strategies through KM utilisation, and away from those based on sources, such as factories, land, machines, raw materials and workforce.

One of the key effects stemming from IT on KM processes is the ability to redirect emphasis of businesses from transactions to strategy, and to do so through enhancing decision-making. Accordingly, knowledge is seen to be a fundamental asset with a foundation of continuous growth, with improved decision-making in this regard able to achieve ongoing, permanent competitive advantage for the firm. As a result, a wealth of knowledge across organisations, predominantly stemming from technology tools, has been recognised as responsible for creating both opportunities and challenges for businesses to leverage knowledge and accordingly enhance decision-making.

\subsection{The IT Component Concept}

Since the time ICT was introduced as a concept, the IT component has been recognised as adopting a key role in terms of improving organisational operation, with the concept of IT infrastructure also commonly directed as a reliable measure for a firm (Han et al., 2017), where IT infrastructure's technological components include applications, data, networks and platforms, with the IT component infrastructure flexibility recognised in terms of compatibility, connectivity and modularity. Moreover, it has been outlined by Tallon and Pinsonneault (2011) that IT infrastructure flexibility further encompasses networks, hardware and software, all of which could have a positive controlling impact in relation to the link between organisational agility and alignment, with particular aspects associated with adaptability and scalability.

The organisation in question is recognised as being in the preliminary stage of making strategic changes from more conventional approaches to new methods, and so doing at different levels, with the IT component recently employed. It has been confirmed in the work of Ezugwu et al. (2016) that ICT can be described as any tool interconnecting computer systems that are used in the automatic acquisition, storage, manipulation management, control, display, switching, and transmission of information across different department within the firm. In a similar vein, the contribution of the IT component in regards information systems that aid employers in completing their tasks and fulfilling their responsibilities has been examined in the work of El Said (2015), with all of these aspects recognised as improving all functions and operations across a firm through their databases, hardware and software, networks, interfaces, training and technical support.

Through practical evidence garnered, the suggestion is made that IT components have been widely used in businesses owing to their recognised potential. In the work carried out by Allameh et al. (2011), emphasis was placed on technology as referring to IT infrastructure and its capacity to support KM processes and Decision-Making through establishing the role adopted by IT in KM processes and Decision-Making. Importantly, IT is recognised as not only extensively used in firms but also as fundamental to firms' operations, which therefore positions IT as a natural medium for facilitating knowledge creation and flow within organisations, and thus as well positioned to aid Decision-Making.

\subsection{The Role of IT Components for Organisation}

The abundance of technological developments witnessed across the IT arena since the 1980s have had a 
significant influence on society across all systems (Dastan, et al. 2011) Furthermore, in line with this, the use of technology across all organisations through the communication process has become fundamental to all Decision-Making in firms. Nonetheless, some organisations continue to lack the most up-to-date technology, with some also in need of more advantaged tools; however, it remains that all firms could benefit from knowledge utilisation if they are to achieve improved Decision-Making. In this regard, it is noted by Porssa and Mirzazadeh (2016) that businesses are directing more and more dependence on the use of various IT-related instruments and resources in mind of enhancing performance, with such tools directed towards information planning, analysis and application in both Decision-Making and management.

Without question, a number of firms have begun to acknowledge, accept and implement IT as pivotal to their success. Nonetheless, it is noted by Ucakturk and Villard (2013) that good management can be achieved through valuable information being fed back through IT use, geared towards enhancing business performance in this setting. In line with this viewpoint, the work of Moreno and Cavazotte (2015) further suggests the potential of knowledge to be codified as information and accordingly stored in computer information systems within a firm; this then can be applied in the knowledge-transfer process as information, with employees across the firm benefitting from knowledge and then partaking in improved employee communication.

\subsection{The Decision-Making Concept}

A number of different theories have been presented in regards Decision-Making in direct consideration to management. Decision-Making, in the view of Litvaj and Stancekova, is recognised as a very complicated process made up of specifically determined actions and phases, each of which gradually stems from the formulation of a particular obstacle seeking a solution and which then seeks to satisfy a goal-the goal being the most optimal solution. Furthermore, Decision-Making may be recognised as a fundamental process in modern management, and can be seen to signify the most fundamental process in amongst the management cycle (Gorzen-Metka, 2014).

Various other academics in the arena, such as Zeinalova (2016), for example, consider the Decision-Making framework as, first and foremost, a behavioural framework geared towards solving problems and making decisions. Moreover, it has been noted by Nowak et al. (2016) that, in a number of different instances, the concept of decision-making warrants the creation of a simpler version of the decision problem framework, and is required across the whole developmental process of any investment project in businesses tackling problem-solving. In essence, Decision-Making can assist and support businesses in providing leaders with more keenly focused advice to achieve greater efficiency amongst staff and management; this is pivotal in establishing a development plan that can satisfy not only the goals of the business but also the needs of the staff. Through KN processes and their utilisation, IT components between system users are seen to be more effective, particularly when coupled with a sound strategic plan.

\subsection{Relationships between Knowledge Management Processes, IT Components and Decision-Making}

It is becoming more and more common for business to approach their goals in consideration to existing technology, their knowledge needs, and their dedication to technology in mind of enhancing decision-making (Alhawari, 2014) . Abubakar et al. (2017) have come to recognise KM as a precise and well-considered strategy centred on organisations achieving efficiency in their knowledge economy. Furthermore, business intelligence is also argued by Wieder and Ossimitz (2015) as able to deliver high-quality information for managerial decision-making through giving thought and attention to establishing/creating, collecting, storing and retrieving, processes and distributing/sharing knowledge that is recognised as valuable to decision-makers. Moreover, knowledge, in line with the Decision-Making process, is recognised as most beneficial across businesses adopting IT management and striving to achieve the integration of business change in IT strategy (Ucakturk \& Villard, 2013)

The analysis processes associated with KM and its effect on the Decision-Making process has been argued in the work of Hossain et al. (2012) as seeking to arrive at various conclusions in regards the possible directions of Decision-Making and technology in line with economic development. Moreover, it is acknowledged by Litvaj \& Stancekova (2015) that KM should be both efficiently and positively utilised across the Decision-Making process with the clear aim to achieve development and enhancements across these processes so as to further achieve management and managerial systems' innovation within the firm through the expansion of technologies and instruments. Furthermore, developments in database management are viewed by Dastan et al. (2011) as having a positive influence on managers' capacity to make decisions, with management able to communicate, transfer and distribute knowledge across all levels of the organisational hierarchy. In this same vein, the application of interactive technology in the knowledge economy field has been highlighted by Li et al. (2012) as 
a critical resource. Accordingly, when applying data-mining, knowledge identified as a result can help to support organisations in enhancing decision-making.

All businesses are known to have knowledge, with specialised knowledge key in the Decision-Making process. As noted in the study by Ferreira et al. (Ferreira \& Neri, 2016) IT has become recognised as a critical aspect for businesses, and is therefore viewed as essential when seeking to optimise levels of quality and IT component efficiency so as to satisfy business expectations through the adoption of reliable and accurate information for Decision-Making. More commonly, businesses possess various fixed ideas in regards the role of IT components. As such, there is a need for databases, hardware, software and telecommunications to be taken into account when reviewing the relationship between KM processes and Decision-Making, and what demands they will put on the system. Moreover, there is a pressing need to garnering insight into the IT components adopted in businesses and the KM processes needed to facilitate Decision-Making.

\section{Hypothesis Development and Research Model}

The following framework has been designed by the researcher, with the inclusion of different variables, as follows: Knowledge Management Processes as independent variables (Knowledge Discovery, Knowledge Capture, Knowledge Storage, Knowledge Sharing, Knowledge Application, and: Knowledge Update), Information Technology components as mediation variable, with Decision-Making as the dependent variable (see Figure 1).

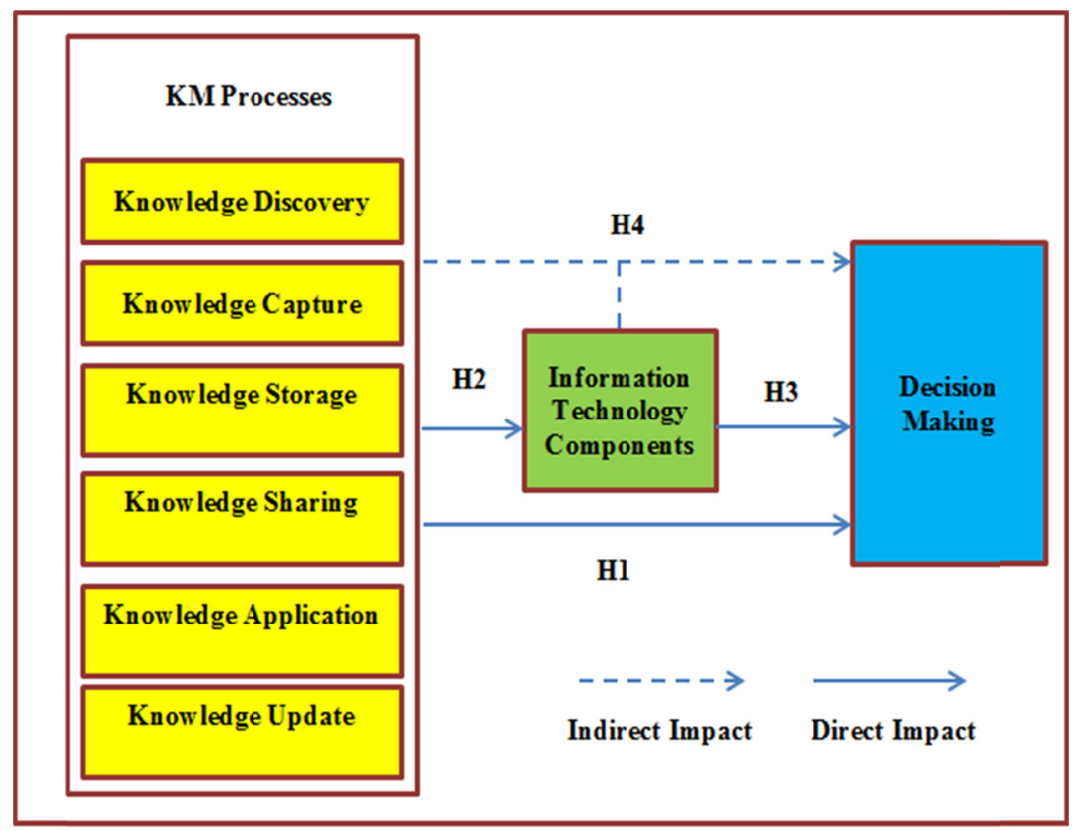

Figure 1. Research model

Primarily, in H1, this paper suggests the direct effects stemming from KM processes and Decision-Making. Accordingly, $\mathrm{H} 1$ is broken down into six different sub-hypotheses. These are outlined as follows:

H1.1: Knowledge Discovery affects Decision-Making at $(\alpha \leq 0.05)$.

H1.2: Knowledge Capture affects Decision-Making at $(\alpha \leq 0.05)$.

H1.3: Knowledge Storage affects Decision-Making at $(\alpha \leq 0.05)$.

H1.4: Knowledge Sharing affects Decision-Making at $(\alpha \leq 0.05)$.

H1.5: Knowledge Application affects Decision-Making at $(\alpha \leq 0.05)$.

H1.6: Knowledge Update affects Decision-Making at $(\alpha \leq 0.05)$.

Secondarily, in $\mathrm{H} 2$, this paper suggests the direct effects stemming from KM processes and IT components. Accordingly, $\mathrm{H} 2$ is broken down into six different sub-hypotheses. These are outlined as follows:

H2.1: Knowledge Discovery affects IT components at $(\alpha \leq 0.05)$. 
H2.2: Knowledge Capture affects IT components at $(\alpha \leq 0.05)$.

H2.3: Knowledge Storage affects IT components at $(\alpha \leq 0.05)$.

H2.4: Knowledge Sharing affects IT components at $(\alpha \leq 0.05)$.

H2.5: Knowledge Application affects IT components at $(\alpha \leq 0.05)$.

H2.6: Knowledge Update affects IT components at $(\alpha \leq 0.05)$.

Thirdly, in H3, this paper suggests the direct effects stemming from IT components and Decision-Making. Accordingly, $\mathrm{H} 3$ is broken down into one further sub-hypotheses. This is outlined as follows:

H3.1: IT Components affects Decision-Making at $(\alpha \leq 0.05)$.

Lastly, in $\mathrm{H} 4$, this paper suggests the direct effects stemming from KM processes by IT components on Decision-Making. Accordingly, H4 is broken down into six different sub-hypotheses. These are outlined as follows:

H4.1: IT components mediates the relation of Knowledge Discovery and Decision-Making at $(\alpha \leq 0.05)$.

H4.2 IT components mediates the relation of Knowledge Capture and Decision Making at ( $\alpha \leq 0.05)$.

H4.3: IT components mediates the relation of Knowledge Storage and Decision Making at $(\alpha \leq 0.05)$.

H4.4: IT components mediates the relation of Knowledge Sharing and Decision Making at $(\alpha \leq 0.05)$.

H4.5: IT components mediates the relation of Knowledge Application and Decision Making at $(\alpha \leq 0.05)$.

H4.6: IT components mediates the relation of Knowledge Update and Decision Making at $(\alpha \leq 0.05)$.

\section{Research Methodology}

A quantitative approach is applied in this work. More specifically, the data are gathered through the adoption of a survey approaches. A questionnaire method has been chosen for data collection in mind of examining the way in which Zain, the telecommunications organisation operating in Jordan, utilised IT components in the relationship between KM processes and Decision-Management. Moreover, the PLS statistical approach has been applied in order complete an analysis on the data gathered throughout this period. Notably, the parameters used to examine the effects of the independent factors on the dependent factor, with the presence of the mediating factor, i.e. IT components, were viewed as most appropriate and aligned with the study objectives.

\subsection{Sample Size}

In direct regard to the organisation under examination in this work, a distribution technique was created in mind of providing an accurate representation of the study population, with this specific strategy taking the sample size $(\mathrm{n}=13)$ and breaking it down. Importantly, 250 questionnaires were distributed, with a total of 200 returned. Notably, 18 were not complete and therefore were not used in the analysis. A total of 182 complete questionnaires therefore made up the questionnaire total.

\section{Data Analysis and Results}

\subsection{Demographic Data Results}

The population utilised in this study was made up of 110 male, representing $60.4 \%$ of the respondents, whilst females $(\mathrm{n}=72)$ made up the remaining percentage of $39.6 \%$. Furthermore, the largest group of respondents (74 or $40.7 \%$ ) were 35 years or older, whilst the smallest group ( 43 or $23.6 \%$ ) were aged $25-30$ years. Moreover, the largest respondent group (100 or 54.9\%) outlined that they held roles in Middle Management, whilst the smallest group in regards managerial level stated other ( 40 or $22 \%$ ), i.e. where they did not recognise themselves to hold roles in Top or Middle management. In terms of years' experience, the largest group of respondents ( 70 or $38.5 \%$ ) stated they had 8-13 years' experience, whilst the smallest group of respondents (52 or 28.6\%) answered 2-7 years in this regard. Table 1 provides an overview of these results. 
Table 1. Demographic data results

\begin{tabular}{llll}
\hline Description & Variable & Result & Percentage \\
\hline \multirow{2}{*}{ Gender } & Male & 110 & $60.4 \%$ \\
& Female & 72 & $39.6 \%$ \\
\multirow{2}{*}{ Age } & $25-30$ & 43 & $23.6 \%$ \\
& $31-35$ & 65 & $35.7 \%$ \\
& More than 35 & 74 & $40.7 \%$ \\
Managerial level & Mop management & 42 & $23.1 \%$ \\
& Middle management & 100 & $54.9 \%$ \\
& Another & 40 & $22.0 \%$ \\
Experience & 2-7 years & 52 & $28.6 \%$ \\
& 8-13 years & 70 & $38.5 \%$ \\
& more than 13 years & 60 & $33.0 \%$ \\
\hline
\end{tabular}

\subsection{Constructs Measurements Analysis}

The Smart Partial Least Square (PLS) software was implemented when it came to analysing the data in line with each of the research hypothesis. Accordingly, data analysis was carried out and tested across two different stages (Hair et al., 2006), with the content, convergent and discriminant validity of variables examined, whilst the data pertaining to the hypotheses underwent testing in line with the study framework.

\subsubsection{Path Loadings for the Proposed Model}

During the initial stage, all factors' path loadings were seen to be more than (0.55), meaning that all of the factors associated with the study framework were correct and could be accepted for analysis (Falk \& Miller, 1992). The results of the path loadings across all of the variables associated with the suggested framework of this study can be seen presented in Figure 2.

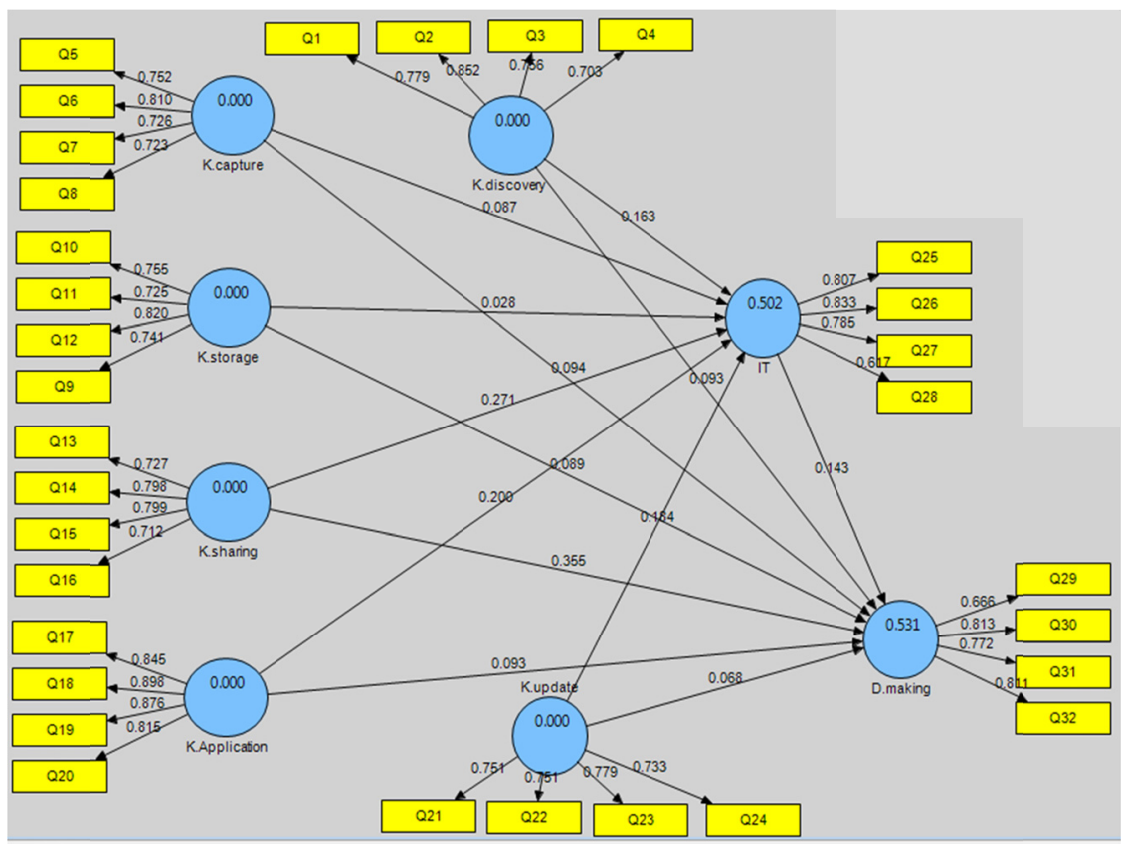

Figure 2. Path loadings for proposed model

The above figure details eight elements, namely Knowledge Management Processes as independent variables (Knowledge Discovery, Knowledge Capture, Knowledge Storage, Knowledge Sharing, Knowledge Application and Knowledge Update), IT components as the mediation variable, with Decision-Making as the dependent 
variable.

Table 2 provides an overview of the study constructs' factor loadings.

Table 2. Constructs measurement

\begin{tabular}{|c|c|c|c|}
\hline Variables & Item & Factors loading & Result \\
\hline \multirow[t]{4}{*}{ Knowledge Discovery } & Q1 & 0.779 & Accept \\
\hline & Q2 & 0.852 & Accept \\
\hline & Q3 & 0.756 & Accept \\
\hline & Q4 & 0.703 & Accept \\
\hline \multirow[t]{4}{*}{ Knowledge Capture } & Q5 & 0.752 & Accept \\
\hline & Q6 & 0.810 & Accept \\
\hline & Q7 & 0.726 & Accept \\
\hline & Q8 & 0.723 & accept \\
\hline \multirow[t]{4}{*}{ Knowledge Storage } & Q9 & 0.741 & accept \\
\hline & Q10 & 0.755 & accept \\
\hline & Q11 & 0.725 & accept \\
\hline & Q12 & 0.820 & accept \\
\hline \multirow[t]{4}{*}{ Knowledge Sharing } & Q13 & 0.727 & accept \\
\hline & Q14 & 0.798 & accept \\
\hline & Q15 & 0.799 & accept \\
\hline & Q16 & 0.712 & accept \\
\hline \multirow{4}{*}{ Knowledge Application } & Q17 & 0.845 & accept \\
\hline & Q18 & 0.898 & accept \\
\hline & Q19 & 0.876 & accept \\
\hline & Q20 & 0.815 & accept \\
\hline \multirow[t]{4}{*}{ Knowledge Update } & Q21 & 0.751 & accept \\
\hline & Q22 & 0.751 & accept \\
\hline & Q23 & 0.779 & accept \\
\hline & Q24 & 0.733 & accept \\
\hline \multirow[t]{4}{*}{ Information Technology components } & Q25 & 0.807 & accept \\
\hline & Q26 & 0.833 & accept \\
\hline & Q27 & 0.785 & accept \\
\hline & Q28 & 0.617 & accept \\
\hline \multirow[t]{4}{*}{ Decision Making } & Q29 & 0.666 & accept \\
\hline & Q30 & 0.813 & accept \\
\hline & Q31 & 0.772 & accept \\
\hline & Q32 & 0.811 & accept \\
\hline
\end{tabular}

In line with Table 4, all of the items detailed were found to exceed 0.55 , meaning all of the items could be accepted owing to the fact that all indicators' standardised path loadings were found to be more than 0.55 and are therefore significant (Falk \& Miller, 1992).

5.2.2 Reliability and Validity Test

A survey design can have a significant influence on the overall reliability and validity associated with the 
research tool. Reliability and validity are simple standards utilised in order to evaluate the study's overall accuracy. In an effort to reduce the possibility that incorrect responses would be received, two specific considerations were made: reliability and validity. In order to ensure the questionnaire could be considered to satisfy both of these aspects, Table 3 outlines the results pertaining to Cronbach's Alpha (CA), Composite Reliability (CR), and Average Variance Extracted (AVE) across all model variables.

When assessing internal consistency reliability, Cronbach's Alpha was utilised as the lower bound of the internal consistency reliability, with all of the CR and CA scores exceeding the suggested value of 0.65 (Nunnally \& Bernstein, 1994), therefore suggesting that all constructs provided sound levels of reliability. One of the most widely implemented criterion of convergent validity is AVE (Fornell \& Larcker, 1981), with an AVE value of 0.50 or greater suggesting the potential of a construct to explain more than half of the variance of its indicators and, thus, displaying suitable levels of convergent validity. Importantly, as can be seen when reviewing Table 3, all of the AVEs ranged $0.56-0.73$, meaning convergent validity was achieved across all variables.

Table 3. Reliability and validity results

\begin{tabular}{|c|c|c|c|}
\hline Constructs & $\begin{array}{l}\text { Cronbach Alpha } \\
\text { (CA) }\end{array}$ & $\begin{array}{l}\text { Average Variance } \\
\text { Extracted (AVE) }\end{array}$ & $\begin{array}{l}\text { Composite Reliability } \\
\text { (CR) }\end{array}$ \\
\hline Knowledge Discovery & 0.77 & 0.60 & 0.85 \\
\hline Knowledge Capture & 0.74 & 0.56 & 0.83 \\
\hline Knowledge Storage & 0.75 & 0.58 & 0.84 \\
\hline Knowledge Sharing & 0.75 & 0.57 & 0.84 \\
\hline Knowledge Application & 0.88 & 0.73 & 0.91 \\
\hline Knowledge Update & 0.74 & 0.56 & 0.84 \\
\hline Information Technology components & 0.75 & 0.58 & 0.84 \\
\hline Decision Making & 0.76 & 0.59 & 0.85 \\
\hline
\end{tabular}

\subsubsection{Discriminant Validity Test}

Latent Variable Correlations was adopted in order to evaluate the discriminant validity, with the suggestion that a construct needs to share a greater degree of variance with its measures than that established across other constructs in a particular framework (Fornell \& Larcker, 1981) [17]. As can be seen in Table 4, greater variance was seen across all constructs with their indicators than in the case of with other constructs.

Table 4. Discriminant validity

\begin{tabular}{|c|c|c|c|c|c|c|c|c|}
\hline Constructs & 1 & 2 & 3 & 4 & 5 & 6 & 7 & 8 \\
\hline Knowledge Discovery & 1.00 & & & & & & & \\
\hline Knowledge Capture & 0.60 & 1.00 & & & & & & \\
\hline Knowledge Storage & 0.46 & 0.48 & 1.00 & & & & & \\
\hline Knowledge Sharing & 0.50 & 0.47 & 0.52 & 1.00 & & & & \\
\hline Knowledge Application & 0.44 & 0.47 & 0.51 & 0.37 & 1.00 & & & \\
\hline Knowledge Update & 0.35 & 0.39 & 0.49 & 0.55 & 0.46 & 1.00 & & \\
\hline Information Technology components & 0.52 & 0.49 & 0.48 & 0.58 & 0.51 & 0.53 & 1.00 & \\
\hline Decision Making & 0.51 & 0.50 & 0.51 & 0.65 & 0.46 & 0.50 & 0.57 & 1.00 \\
\hline
\end{tabular}

Where 1: Knowledge Discovery; 2: Knowledge Capture; 3: Knowledge Storage; 4: Knowledge Sharing; 5: Knowledge Application; 6: Knowledge Update; 7: Information Technology components; 8: Decision Making.

In line with that displayed in Table 4, it may be seen that satisfactory discriminant validity can be identified, with all of the correlation coefficients not exceeding 0.8 , so as to ensure multicollinearity between factors is not present. The correlation coefficient in excess of 0.80 would imply there is an issue in terms of multicollinearit. Following the measurement model with the inclusion of all of its parameters (as highlighted above) undergoing 
testing, the framework was found to be both valid and reliable.

\subsubsection{R (Square) Test}

Path coefficient results' values provide a rationale for the link amongst all factors in line with those mediation factors used and not used. Accordingly, it was not considered necessary to implement the R (Square) test when describing these relations. The table below provides an explanation for the $\mathrm{R}$ (Square) values.

Table 5. R (Square) value

\begin{tabular}{l}
\hline Relation \\
\hline Influence of Knowledge Management (KM) Processes on Decision Making without mediation by Information 0.50 \\
Technology (IT) components \\
Influence of Knowledge Management (KM) Processes on Decision Making with mediation by Information 0.53 \\
Technology (IT) components
\end{tabular}

The R (Square) values associated with the variable (Decision-Making) without the application of IT components as a mediation variable was seen to be $(0.50)$, meaning it exceeded $(25 \%)$; this therefore represents an accepted and satisfactory prediction level in line with what has been recommended in the work of Gaur \& Gaur (2006). Furthermore, in regards the R (Square) value linked to the Decision-Making variable and with the adoption of IT components as a mediation variable, the value was found to be $(0.53)$, which therefore exceeded $(25 \%)$; this therefore represents an accepted and satisfactory prediction level in line with that recommended in the work of Gaur and Gaur (2006). Moreover, the R (Square) value increased from 50\% to 53\%, meaning the IT components variable demonstrated an increase in terms of the $\mathrm{R}$ (Square) percentage by approximately $25 \%$ when applied as the mediation variable in the suggested framework.

\subsection{Hypotheses Testing}

The logical analysis was adopted in this work in order to complete testing on the suggested framework so as to ensure a comprehensive clarification of the findings associated with the hypotheses through the adoption of the Bootstrapping analysis in smart PLS software.

Primarily, the rate of T value across all KM processes on Decision-Making, without the use of IT components as a mediation factor, was determined. This is shown in Figure 3.

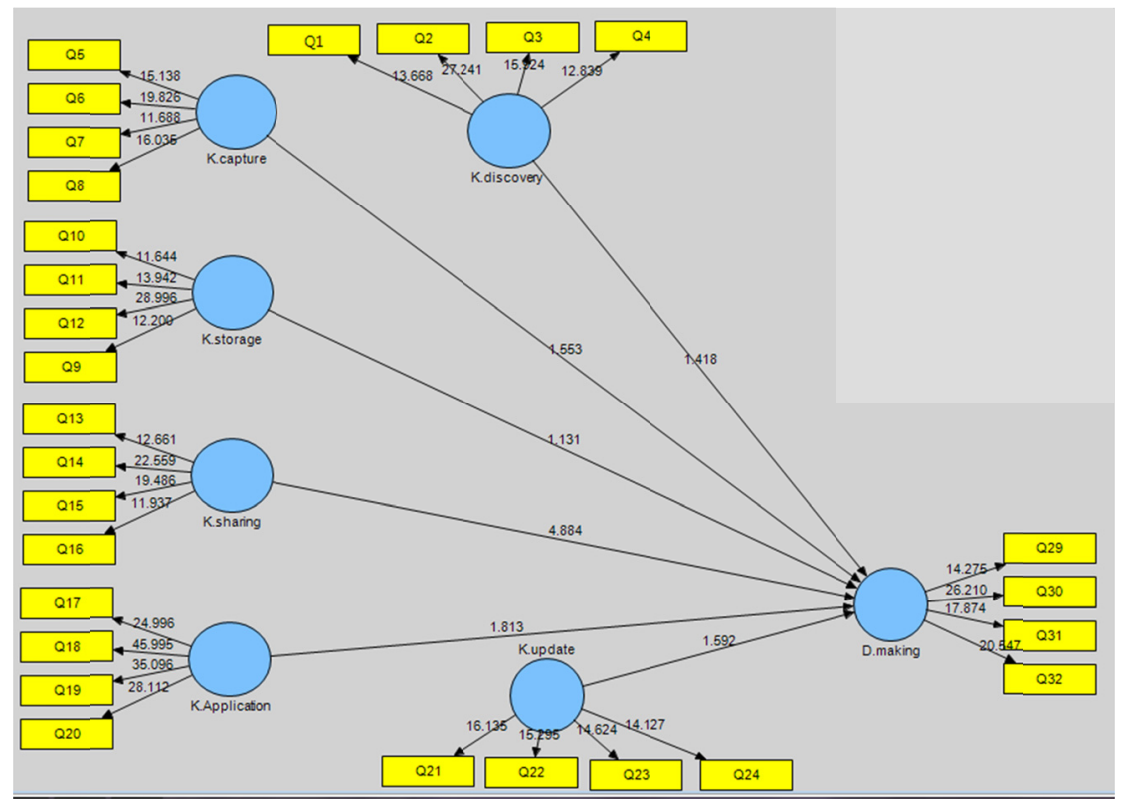

Figure 3. Bootstrapping (T value) for Knowledge Management (KM) Processes on Decision Making without mediation by Information Technology (IT) components

In line with Figure 3, the rate of the $\mathrm{T}$ value was presented by the author in order to test the hypotheses 
associated with the various factors, namely Knowledge Management (KM) Processes (Knowledge Discovery, Knowledge Capture, Knowledge Storage, Knowledge Sharing, Knowledge Application and Knowledge Update), with Decision-Making without using IT components as the mediation variable. The value of these results can be seen displayed in Table 6.

Table 6. Test results of Knowledge Management (KM) Processes and Decision Making without using Information Technology (IT) components as a mediation variable

\begin{tabular}{lll}
\hline Relation (direct effect) & T value & Beta value \\
\hline Knowledge Discovery --> Decision Making & 1.14 & 0.09 \\
Knowledge Capture -->Decision Making & 1.55 & 0.09 \\
Knowledge Storage -->Decision Making & 1.13 & 0.08 \\
Knowledge Sharing -->Decision Making & 4.88 & 0.35 \\
Knowledge Application -->Decision Making & 1.81 & 0.09 \\
Knowledge Update -->Decision Making & 1.59 & 0.06 \\
\hline
\end{tabular}

The results detailed in the above table provide validation for H1.1: Knowledge Discovery affects Decision-Making. The statistic's T value of (1.14), and the (Beta) Value ratio was (0.09); this highlights that change in Knowledge Discovery will rationalise change of (0.09) in Decision-Making. Accordingly, Knowledge Discovery has a positive influence on Decision-Making in the context of the telecommunications organisation Zain, operating in Jordan.

The results detailed in the above table provide validation for H1.2: Knowledge Capture affects Decision-Making. The statistic's T value of (1.55), and the (Beta) Value ratio was (0.09); this highlights that change in Knowledge Capture will rationalise change of (0.09) in Decision-Making. Accordingly, Knowledge Capture has a positive influence on Decision-Making in the context of the telecommunications organisation Zain, operating in Jordan.

The results detailed in the above table provide validation for H1.3: Knowledge Storage affects Decision-Making. The statistic's $T$ value of (1.13), and the (Beta) Value ratio was (0.08); this highlights that change in Knowledge Storage will rationalise change of (0.08) in Decision-Making. Accordingly, the Knowledge Storage has a positive influence on Decision-Making in the context of the telecommunications organisation Zain, operating in Jordan.

The results detailed in the above table provide validation for H1.4: Knowledge Sharing affects Decision-Making. The statistic's T value of (4.88), and the (Beta) Value ratio was (0.35); this highlights that change in Knowledge Sharing will rationalise change of (0.35) in Decision-Making. Accordingly, Knowledge Sharing has a positive influence on Decision-Making in the context of the telecommunications organisation Zain, operating in Jordan.

The results detailed in the above table provide validation for H1.5: Knowledge Application affects Decision-Making. The statistic's T value of (1.81), and the (Beta) Value ratio was (0.09); this highlights that change in Knowledge Application will rationalise change of (0.09) in Decision-Making. Accordingly, the Knowledge Application has a positive influence on Decision-Making in the context of the telecommunications organisation Zain, operating in Jordan.

Lastly, the results detailed in the above table provide validation for H1.6: Knowledge Update affects Decision-Making. The statistic's T value of (1.59), and the (Beta) Value ratio was (0.06); this highlights that change in Knowledge Update will rationalise change of (0.06) in Decision-Making. Accordingly, the Knowledge Update has a positive influence on Decision-Making in the context of telecommunications organisation Zain, operating in Jordan.

Furthermore, the test established the ( $\mathrm{T}$ value) for $\mathrm{KM}$ processes on Decision-Making with the use of IT components as a mediation variable. This can be seen represented in Figure 4. 


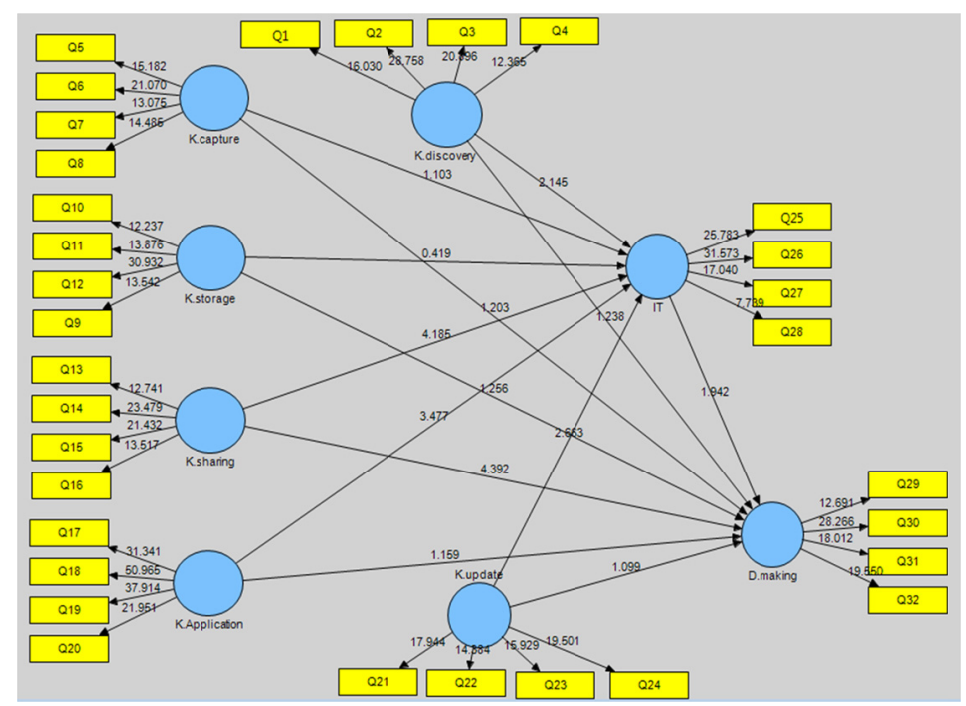

Figure 4. Bootstrapping ( $\mathrm{T}$ value) for Knowledge Management (KM) Processes on Decision Making with mediation by Information Technology (IT) components

In line with Figure 4, the researcher established the ( $\mathrm{T}$ value) test through the application of the Smart Partial Least Square (PLS), testing all hypotheses associated with the six KM Processes (Knowledge Discovery, Knowledge Capture, Knowledge Storage, Knowledge Sharing, Knowledge Application and Knowledge Update), and Information Technology (IT) components. Table 7 provides an overview of the results in this regard.

Table 7. Test results of Knowledge Management (KM) Processes and Information Technology (IT) components

\begin{tabular}{lcc}
\hline Relation (direct effect) & T value & Beta value \\
\hline Knowledge Discovery -->Information Technology (IT) components & 2.14 & 0.16 \\
Knowledge Capture -->Information Technology (IT) components & 1.10 & 0.08 \\
Knowledge Storage -->Information Technology (IT) components & 0.41 \\
Knowledge Sharing -->Information Technology (IT) components & 4.18 \\
Knowledge Application -->Information Technology (IT) components & 3.47 \\
Knowledge Update -->Information Technology (IT) components & 2.66 & 0.02 \\
\hline
\end{tabular}

The results detailed in the above table provide validation for H2.1: Knowledge Discovery affects IT components. The statistic's T value of (2.14), and the (Beta) Value ratio was (0.16); this highlights that change in Knowledge Discovery will rationalise change of (0.16) in IT components. Accordingly, Knowledge Discovery has a positive influence on IT components in the context of telecommunications organisation Zain, operating in Jordan.

The results detailed in the above table provide validation for H2.2: Knowledge Capture affects IT components. The statistic's T value of (1.10), and the (Beta) Value ratio was (0.08); this highlights that change in Knowledge Capture will rationalise change of (0.08) in IT components. Accordingly, Knowledge Capture has a positive influence on IT components in the context of telecommunications organisation Zain, operating in Jordan.

The results detailed in the above table provide validation for H2.3: Knowledge Storage affects IT components. The statistic's T value of (0.41), and the (Beta) Value ratio was (0.02); this highlights that change in Knowledge Storage will rationalise change of (0.02) in IT components. Accordingly, Knowledge Storage has a positive influence on IT components in the context of telecommunications organisation Zain, operating in Jordan.

The results detailed in the above table provide validation for H2.4: Knowledge Sharing affects IT components. The statistic's T value of (4.18), and the (Beta) Value ratio was (0.27); this highlights that change in Knowledge Sharing will rationalise change of (0.27) in IT components. Accordingly, Knowledge Sharing has a positive influence on IT components in the context of telecommunications organisation Zain, operating in Jordan.

The results detailed in the above table provide validation for H2.5: Knowledge Application affects IT components. The statistic's T value of (3.47), and the (Beta) Value ratio was (0.20); this highlights that change in Knowledge Application will rationalise change of (0.20) in IT components. Accordingly, Knowledge Application 
has a positive influence on IT components in the context of telecommunications organisation Zain, operating in Jordan.

Lastly, the results detailed in the above table provide validation for H2.6: Knowledge Update affects IT components. The statistic's T value of (2.66), and the (Beta) Value ratio was (0.18); this highlights that change in Knowledge Update will rationalise change of (0.18) in IT components. Accordingly, Knowledge Update has a positive influence on IT components in the context of telecommunications organisation Zain, operating in Jordan.

As can be seen in Figure 4, the (T value) test was applied in the Smart Partial Least Square (PLS) in an effort to analyse the hypothesis related to IT components in Decision-Making. An overview of the results can be seen displayed in Table 8.

Table 8. Test results for Information Technology (IT) components and Decision Making

\begin{tabular}{lll}
\hline Relation (direct effect) & T value & Beta value \\
\hline Information Technology (IT) components --> Decision Making & 1.94 & 0.14 \\
\hline
\end{tabular}

The results detailed in the above table provide validation for H3: IT components affect Decision-Making. The statistic's $T$ value of (1.94), and the (Beta) Value ratio was (0.14); this highlights that change in IT components will rationalise change of (0.14) in Decision-Making. Accordingly, IT components have a positive influence on Decision-Making in the context of telecommunications organisation Zain, operating in Jordan.

Lastly, the analysis results detailed in the previous section have highlighted the application of the $\mathrm{T}$ value test result by the Smart Partial Least Square (PLS) in determining the mediating role of the variable IT components in the link between KM processes (Knowledge Discovery, Knowledge Capture, Knowledge Storage, Knowledge Sharing, Knowledge Application and Knowledge Update) on Decision-Making. Table 9-14 provide an overview of these results, respectively.

Table 9. Test results for Knowledge Discovery and Decision Making mediating by Technology (IT) components

\begin{tabular}{|c|c|c|c|c|c|}
\hline Relation(direct and indirect) & $\begin{array}{l}\text { Direct } \\
\text { effect } \\
\text { T value }\end{array}$ & $\begin{array}{l}\text { Direct } \\
\text { effect } \\
\text { Beta }\end{array}$ & $\begin{array}{l}\text { Indirect } \\
\text { effect } \\
\text { Beta }\end{array}$ & $\begin{array}{l}\text { Total } \\
\text { effect } \\
\text { T value }\end{array}$ & $\begin{array}{l}\text { Total } \\
\text { effect } \\
\text { Beta }\end{array}$ \\
\hline Knowledge Discovery --> Information Technology (IT) components & 2.14 & 0.16 & & 2.14 & 0.16 \\
\hline Information Technology (IT) components --> Decision Making & 1.94 & 0.14 & & 1.94 & 0.14 \\
\hline $\begin{array}{l}\text { Knowledge Discovery }-->\text { Decision Making mediating by } \\
\text { Information Technology (IT) components }\end{array}$ & & & 0.022 & & \\
\hline & 1.14 & & & & \\
\hline Knowledge Discovery -->Decision Making & $\begin{array}{l}\text { Fully } \\
\text { mediate }\end{array}$ & 0.09 & & 1.50 & 0.112 \\
\hline
\end{tabular}

The results detailed in the above table provide validation for H4.1: IT components affect the relation of Knowledge Discovery and Decision-Making at $(\alpha \leq 0.05)$ with Knowledge Discovery affecting IT components. The statistic's T value of (2.14) and Information Technology (IT) components were found to have a significant influence on Decision-Making, demonstrating the statistic's T value of (1.94). Furthermore, the (Beta) Value ratio for (Indirect Effect) is (0.022); this highlights that change in Knowledge Discovery and Information Technology (IT) components will rationalise change of (0.022) in Decision-Making. As a result, IT components can be seen to play a complete mediating role in the link between Knowledge Discovery and Decision-Making in the context of telecommunications organisation Zain, operating in Jordan. 
Table 10. Test results for Knowledge Capture and Decision Making mediating by Technology (IT) components

\begin{tabular}{|c|c|c|c|c|c|}
\hline Relation(direct and indirect) & $\begin{array}{l}\text { Direct } \\
\text { effect } \\
\text { T value }\end{array}$ & $\begin{array}{l}\text { Direct } \\
\text { effect } \\
\text { Beta }\end{array}$ & $\begin{array}{l}\text { Indirect } \\
\text { effect } \\
\text { Beta }\end{array}$ & $\begin{array}{l}\text { Total } \\
\text { effect } \\
\text { T value }\end{array}$ & $\begin{array}{l}\text { Total } \\
\text { effect } \\
\text { Beta }\end{array}$ \\
\hline Knowledge Capture --> Information Technology (IT) components & 1.10 & 0.08 & & 1.10 & 0.08 \\
\hline Information Technology (IT) components --> Decision Making & 1.94 & 0.14 & & 1.94 & 0.14 \\
\hline $\begin{array}{l}\text { Knowledge Capture --> Decision Making mediating by Information } \\
\text { Technology (IT) components }\end{array}$ & & & 0.011 & & \\
\hline & 1.55 & & & & \\
\hline Knowledge Capture -->Decision Making & $\begin{array}{l}\text { Not } \\
\text { mediate }\end{array}$ & 0.09 & & 1.38 & 0.101 \\
\hline
\end{tabular}

The results detailed in the above table provide validation for H4.2: IT components do not influence the link of Knowledge Capture and Decision-Making at $(\alpha \leq 0.05)$, with Knowledge Capture not seen to influence IT components. The statistic's T value of (1.10) and Information Technology (IT) components affect Decision Making, with the statistic's T value seen to be (1.94). Furthermore, the (Beta) Value ratio for (Indirect Effect) is (0.011); this highlights that change in Knowledge Capture and IT components will rationalise change of $(0.011)$ in Decision-Making. Accordingly, IT components are not viewed as playing a mediating role between Knowledge Capture and Decision-Making in the context of telecommunications organisation Zain, operating in Jordan.

Table 11. Test results for Knowledge Storage and Decision Making mediating by Technology (IT) components

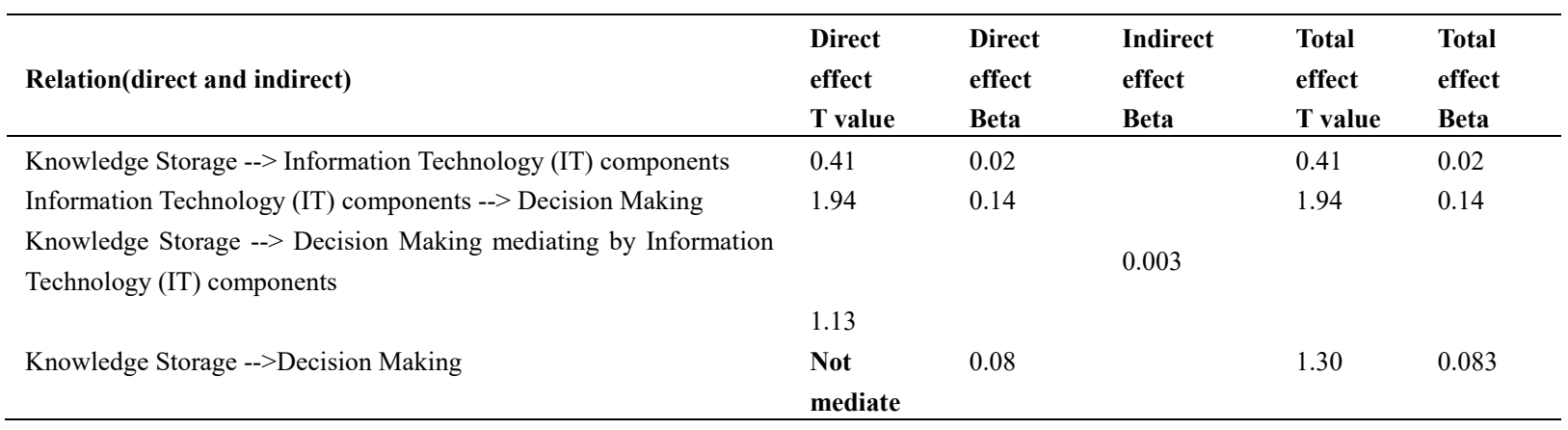

The results detailed in the above table provide validation for H4.3: IT components are not seen to have a significant effect on the link of Knowledge Storage and Decision Making at $(\alpha \leq 0.05)$, with Knowledge Storage not influencing IT components. The statistic's T value of (0.41) and Information Technology (IT) components were found to have a significant influence on Decision-Making, where the statistic's $\mathrm{T}$ value of (1.94). Furthermore, the (Beta) Value ratio for (Indirect Effect) is (0.003); this highlights that change in Knowledge Storage and IT components will rationalise change of (0.003) in Decision-Making. As a result, IT components are not seen to play a mediatory role between Knowledge Storage and Decision-Making in the context of telecommunications organisation Zain, operating in Jordan.

Table 12. Test results for Knowledge Sharing and Decision Making mediating by Technology (IT) components

\begin{tabular}{|c|c|c|c|c|c|}
\hline Relation(direct and indirect) & $\begin{array}{l}\text { Direct effect } \\
\text { T value }\end{array}$ & $\begin{array}{l}\text { Direct } \\
\text { effect } \\
\text { Beta }\end{array}$ & $\begin{array}{l}\text { Indirect } \\
\text { effect } \\
\text { Beta }\end{array}$ & $\begin{array}{l}\text { Total } \\
\text { effect } \\
\text { T value }\end{array}$ & $\begin{array}{l}\text { Total } \\
\text { effect } \\
\text { Beta }\end{array}$ \\
\hline Knowledge Sharing --> Information Technology (IT) components & 4.18 & 0.27 & & 4.18 & 0.27 \\
\hline Information Technology (IT) components --> Decision Making & 1.94 & 0.14 & & 1.94 & 0.14 \\
\hline $\begin{array}{l}\text { Knowledge Sharing --> Decision Making mediating by } \\
\text { Information Technology (IT) components }\end{array}$ & & & 0.038 & & \\
\hline & 4.88 & & & & \\
\hline Knowledge Sharing --> Decision Making & $\begin{array}{l}\text { Partially } \\
\text { mediate }\end{array}$ & 0.35 & & 5.06 & 0.388 \\
\hline
\end{tabular}


The results detailed in the above table provide validation for H4.4: IT components affect the relation of Knowledge Sharing and Decision-Making at ( $\alpha \leq 0.05)$, with Knowledge Sharing seen to affect IT components, where the statistic's T value of (4.18) and IT components significantly affect Decision Making. The statistic's T value of (1.94). Furthermore, the (Beta) Value ratio for (Indirect Effect) is (0.038); this highlights that change in Knowledge Sharing and IT components can rationalise change of (0.038) in Decision-Making. Accordingly, IT components can be seen to adopt a partial mediatory role between Knowledge Sharing and Decision-Making in the context of telecommunications organisation Zain, operating in Jordan.

Table 13. Test results for Knowledge Application and Decision Making mediating by Technology (IT) components

\begin{tabular}{|c|c|c|c|c|c|}
\hline Relation(direct and indirect) & $\begin{array}{l}\text { Direct effect } \\
\text { T value }\end{array}$ & $\begin{array}{l}\text { Direct } \\
\text { effect } \\
\text { Beta }\end{array}$ & $\begin{array}{l}\text { Indirect } \\
\text { effect } \\
\text { Beta }\end{array}$ & $\begin{array}{l}\text { Total } \\
\text { effect } \\
\text { T value }\end{array}$ & $\begin{array}{l}\text { Total } \\
\text { effect } \\
\text { Beta }\end{array}$ \\
\hline $\begin{array}{l}\text { Knowledge Application }-->\text { Information Technology (IT) } \\
\text { components }\end{array}$ & 3.47 & 0.20 & & 3.47 & 0.20 \\
\hline $\begin{array}{l}\text { Information Technology (IT) components --> Decision Making } \\
\text { Knowledge Application --> Decision Making mediating by } \\
\text { Information Technology (IT) components }\end{array}$ & 1.94 & 0.14 & 0.028 & 1.94 & 0.14 \\
\hline Knowledge Application -->Decision Making & $\begin{array}{l}1.81 \\
\text { Partially } \\
\text { mediate }\end{array}$ & 0.09 & & 1.65 & 0.118 \\
\hline
\end{tabular}

The results detailed in the above table provide validation for H1.5: IT components affect the relation of Knowledge Application and Decision-Making at $(\alpha \leq 0.05)$, with Knowledge Application affecting IT components in which the statistic's T value of (3.47) and Information Technology (IT) components have a significant effect on Decision-Making, where the statistic's T value of (1.94). Furthermore, the (Beta) Value ratio for (Indirect Effect) is (0.028); this highlights that change in Knowledge Application and IT components will rationalise change of (0.028) in Decision-Making. Accordingly, IT components can be seen to adopt a partially mediatory role in the link between Knowledge Application and Decision-Making in the context of telecommunications organisation Zain, operating in Jordan.

Table 14. Test results for Knowledge Update and Decision Making mediating by Technology (IT) components

\begin{tabular}{|c|c|c|c|c|c|}
\hline Relation(direct and indirect) & 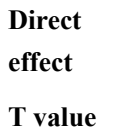 & $\begin{array}{l}\text { Direct } \\
\text { effect }\end{array}$ & $\begin{array}{l}\text { Indirect } \\
\text { effect } \\
\text { Beta }\end{array}$ & $\begin{array}{l}\begin{array}{l}\text { Total } \\
\text { effect }\end{array} \\
\text { T value }\end{array}$ & $\begin{array}{l}\text { Total } \\
\text { effect }\end{array}$ \\
\hline Knowledge Update --> Information Technology (IT) components & 2.14 & 0.16 & \multirow{5}{*}{0.029} & 2.14 & 0.16 \\
\hline Information Technology (IT) components --> Decision Making & 2.66 & 0.18 & & 2.66 & 0.18 \\
\hline $\begin{array}{l}\text { Knowledge Update --> Decision Making mediating by Information } \\
\text { Technology (IT) components }\end{array}$ & & & & & \\
\hline & 1.59 & & & & \\
\hline Knowledge Update -->Decision Making & $\begin{array}{l}\text { Fully } \\
\text { mediate }\end{array}$ & 0.06 & & 1.46 & 0.089 \\
\hline
\end{tabular}

The results detailed in the above table provide validation for H4.6: IT components affect the relation of Knowledge Update and Decision-Making at ( $\alpha \leq 0.05)$, with Knowledge Update affecting IT components in which the statistic's T value of (2.14) and IT components can be seen to have a significant influence on Decision-Making, where the statistic's T value is (1.94). Furthermore, the (Beta) Value ratio for (Indirect Effect) is (0.029); this highlights that change in Knowledge Update and IT components will rationalise change of (0.029) in Decision-Making. Accordingly, IT components can be seen to play an entirely mediatory role between Knowledge Update and Decision-Making in the context of telecommunications organisation Zain, operating in Jordan. 


\section{Discussion, Implication and Conclusion}

This report provides a new and fresh effort in the literature, centred on providing an empirical evaluation of KM processes in line with IT components and Decision-Making. Essentially, this paper has investigated and examined opportunities that are available when seeking to improve and enhance decision-making in relation to KM processes and IT components within the business environment. As a result, this report has completed a sound investigation into the influences recognisable between those constructs associated with KM processes as independent variables (Knowledge Discovery, Knowledge Capture, Knowledge Storage, Knowledge Sharing, Knowledge Application and Knowledge Update), and Information Technology components as a mediation variable, with Decision Making as a dependent variable.

The findings garnered through the completion of the analysis were achievable owing to combining Knowledge Discovery and Knowledge Update, with IT components providing a completely mediatory role in the context of telecommunications organisation Zain, operating in Jordan. This has provided a valuable and significant strategy to decision-making. In contrast, the analysis findings would otherwise have been unobtainable had there not been the integration of Knowledge Sharing and Knowledge Application, with IT components providing partial mediation in the context of telecommunications organisation Zain, operating in Jordan. This has provided a valuable and significant strategy to decision-making. Importantly, however, the link between IT components and Decision-Making is not mediated by Knowledge Capture and Knowledge Storage. Accordingly, this paper provides a contribution to the literature, knowledge base and theory; this has been achieved through a literature review and establishing the various frameworks and data analysis discussed in other works. In which it provide an integrated model combines the IT components presented in many literature as Dastan (2011) and Capalbo et, al (2017) and the decision making components presented by (Alhawari, 2014), and many other researchers in the field. Moreover this model presented in this research also integrates knowledge Processes with this two factors (IT components and decision making). It is such work that has allowed the researcher to devise a new framework with the capacity to rationalise and predict direct and indirect influences between constructs. Furthermore, a real organisation has provided a real case scenario, facilitating accurate testing of the model. This has further reinforced model evaluation.

As can be seen from the findings garnered in this work, the researcher would suggest that management-whether at top or middle levels - collaborate in consideration to those fully mediating IT components with Knowledge Discovery and Knowledge Update when seeking to achieve sound Decision-Making - specifically in the context of telecommunications organisation Zain, operating in the context of Jordan, this indicate one of the advantages of this study. However

\section{References}

Abubakar, A. M., Elrehail, H., Alatailat, M. A., \& Elci, A. (2017) Knowledge management, decision-making style and organizational performance. Journal of Innovation \& Knowledge. http://dx.doi.org/10.1016/j.jik.2017.07.003

Ahani, M., Bahrami, H., \& Shariflu, B. (2013). Determining the dimension of knowledge management implementation by utilizing a fuzzy TOPSIS method. International Journal of Business Administration, 4(1), 113-123.

Alharithy, M. (2015). Knowledge Management Process in several organizations: Analytical Study of modeling and several processes. Procedia Computer Science, 65, 726-733.

Alhawari, S., \& Al-Jarrah, M. (2012). The Impact of Knowledge Management Processes on the Improve of Strategic Competence: An Empirical study In Jordanian Insurance Companies. International Journal of Trade, Economics and Finance (IJTEF), 3(1), 39-45.

Alhawari, S., (2014). Improving decision for banking to support customer knowledge retention: a quantitative study in Jordanian banking sector. International Journal Electronic Customer Relationship Management, $8(1 / 2 / 3), 119-135$.

Alhawari, S., Karadsheh, L., Talet, A. N., \& Mansour, E., (2012) Knowledge-Based Risk Management Framework for Information Technology Project. International Journal of Information Management, 32(1), $50-65$.

Allameh, S. M., Zare, S. M., \& Davoodi, S. M. (2011) Examining the Impact of KM Enablers on Knowledge Management Processes. Procedia Computer Science, 3, 1211-1223.

Capalbo, S. M., Antle, J. M., \& Seavert, C. (2017) Next generation data systems and knowledge products to 
support agricultural producers and science-based policy decision making. Agricultural Systems, 155, 191-199.

Cerchione, R., \& Esposito, E. (2017). Using knowledge management systems: A taxonomy of SME strategies. International Journal of Information Management, 37, 1551-1562.

Dalmarco, G., Maehler, A. E., Trevisan, M., \& Schiavini, J. M. (2017). The use of knowledge management practices by Brazilian startup companies. RAI Revista de Administração e Inovação, 14, 226-234.

Dastan, I., Cicek, M., \& Naralan, A. (2011). The Effects of Information Technology Supported Education on Strategic Decision Making: An Empirical Study. Procedia Social and Behavioral Sciences, 24, 1134-1142.

Dos Santos, C. F., Piechnicki, F., Loures, E., \& Santos, E. (2017). Mapping the conceptual relationship among data analysis, knowledge generation and decision-making in industrial processes. Procedia Manufacturing, 11, 1751-1758.

El Said, G. R. (2015). Understanding Knowledge Management System antecedents of performance impact: Extending the Task-technology Fit Model with intention to share knowledge construct. Future Business Journal, 1, 75-87

Ezugwu, A. E., Ofem , P. O., Rathod, P., Agushaka, J. O., \& Haruna, S. (2016) An Empirical Evaluation of the Role of Information and Communication Technology in Advancement of Teaching and Learning. Procedia Computer Science, 92, 568-577.

Falk, R. F., \& Miller, N. B. (1992). A Primer for Soft Modeling. The University of Akron Press.

Ferreira, C., Nery, A., \& Pinheiro, P. R. (2016). A Multi-Criteria Model in Information Technology Infrastructure Problems. Procedia Computer Science, 9, 642-651.

Fornell, C., \& Larcker, D. F. (1981). Evaluating Structural Equations Models with Unobservable Variables and Measurement Error. Journal of Marketing Research, 18(1), 39-50.

Gaur. A. S., \& Gaur. S. S. (2006). Statistical Methods for Practice and Research: A Guide to Data Analvsis using SPSS (1st ed.). Thousand Oaks, California: Sag.

Gorzen-Mitka, I., \& Okre, M. (2014). Improving Decision Making in Complexity Environment. Procedia Economics and Finance, 16, 402-409.

Gulkan, M. G. (2008). Participating the Decision Making Process in Educational Management (The Ministry of National Education Case). World Applied Sciences Journal, 3(6), 939-944.

Hair, J. F., Black, B., Babin, B., Anderson, R. E., \& Tatham, R. L. (2006). Multivariate Data Analysis (6th ed.). New Jersey: Pearson Prentice Hall.

Han, J. H., Wang, Y., \& Naim, M. (2017). Reconceptualization of information technology flexibility for supply chain management: An empirical study. International Journal of Production Economics, 187, 196-215.

Horita, F. E., Albuquerque, J. P., Marchezini, V., \& Mendiondo, E. M. (2017). Bridging the gap between decision-making and emerging big data sources: An application of a model-based framework to disaster management in Brazil. Decision Support Systems, 97, 12-22.

Hossain, N., Sarkani, S., \& Mazzuchi, T. A. (2012) The Integration and Impact of Effective Knowledge Management Systems in the Advancement of the Decision Making Process in Complex Organizations to Realize Economic Growth. Procedia Computer Science, 8, 100-105.

Janssen, S. J., Porter, C. H., Moore, A. D., Athanasiadis, I. N., Foster, I., Jones, J. W., \& Antle, J. M. (2017). Towards a new generation of agricultural system data, models and knowledge products: Information and communication technology. Agricultural Systems, 155, 200-212.

Kiatsuranon, K., \& Suwunnamek, O. (2017). Determinants of Thai information and communication technology organization performance: A structural equation model analysis. Kasetsart Journal of Social Sciences, 1-8.

Lai, Y. L., \& Lin, F. J. (2012). The Effects of Knowledge Management and Technology Innovation on New Product Development Performance: An Empirical Study of Taiwanese Machine Tools Industry. Procedia Social and Behavioral Sciences, 40, 157-164.

Li, X., Zhu, Z., \& Pan, X. (2012). Knowledge Cultivating for Intelligent Decision Making in Small \& Middle Businesses. Procedia Computer Science, 1, 2479-2488.

Litvaj, I., \& Stancekova, D. (2015). Decision - Making, and Their Relation to The Knowledge Management, 
Use of Knowledge Management in Decision - Making. Procedia Economics and Finance, 23, 467-472.

Marinagi, C., Trivellas, P., \& Sakas, D. P. (2014). The impact of Information Technology on the development of Supply Chain Competitive Advantage. Procedia - Social and Behavioral Sciences, 147, 586-591.

Merlo, T. R. (2016). Factors influencing Knowledge Management use in Technology enterprises in Southern United States. Procedia Computer Science, 99, 15-35.

Moreno, V., \& Cavazotte, F. (2015). Using Information Systems to Leverage Knowledge Management Processes: The Role of Work Context. Procedia Computer Science, 55, 360-369.

Naicker, V. (2013). Uncovering knowledge management prac-tices in organizations. Journal of Applied Business Research. http://dx.doi.org/10.19030/jabr.v29i6.8221

Nonaka, I. (1994). A Dynamic Theory of Organizational Knowledge Creation. Organization Science, 5(1), 14-37.

Novickis, L., Mitasiunas, A., \& Ponomarenko, V. (2015). Towards Knowledge and Information Technology Transfer Concept and Its Validation. Procedia Computer Science, 77, 48-55.

Nowak, P., Ksiazek, M., Draps, M., \& Zawistowski, J. (2016). Decision Making with use of Building Information Modeling. Procedia Engineering, 153, 519-526,

Nunnally, J. C., \& Bernstein, I. H. (1994). Psychometric Theory. New York: McGraw-Hill.

Pereira, S. D., \& Quoniam, L. (2017). Intellectual property and patent prospecting as a basis for knowledge and innovation - a study on mobile information technologies and virtual processes of communication and management. RAI Revista de Administração e Inovação, 14, 301-310.

Piechnicki, F., Loures, E., \& Santos, E. (2017). A conceptual framework of knowledge conciliation to decision making support in RCM deployment. Procedia Manufacturing, 11, 1135-1144.

Porssa, A., \& Mirzazadeh, H. (2016). Develop an Information Technology Model to Improve Customer Service in NIGCS. Procedia - Social and Behavioral Sciences, 229, 167-174.

Said, A. R., Abdullah, H., Uli, J., \& Mohamed, Z. A. (2014). Relationship between Organizational Characteristics and Information Security Knowledge Management Implementation. Procedia - Social and Behavioral Sciences, 123, 33-443.

Sallan, G. J., Alava, M. F., Barrera-Corominas, A., \& Rodríguez-Gómez, D. (2012). Review of Knowledge Creation and Management processes through communities of practice in Public Administration. Procedia Social and Behavioral Sciences, 46, 2198-2204.

Tallon, P. P., \& Pinsonneault, A. (2011). Competing perspectives on the link between strategic information technology alignment and organizational agility: Insights from a mediation model. MIS Q. 35(2), 463-484.

Torabi, F., \& El-Den, J. (2017). The impact of Knowledge Management on Organizational Productivity: A Case Study on Koosar Bank of Iran. Procedia Computer Science, 124, 300-310.

Tubigi, M., \& Alshawi, S. (2012). The impact of knowledge management processes on Organisational performance. European. Mediterranean \& Middle Eastern Conference on Information Systems, 747-762.

Ucakturk, A., \& Villard, M. (2013). The Effects of Management Information and ERP Systems on Strategic Knowledge Management and Decision-Making. Procedia - Social and Behavioral Sciences, 99, 1035-1043.

Wieder, B., \& Ossimitz, M. L. (2015). The impact of Business Intelligence on the quality of decision making - a mediation model, The impact of Business Intelligence on the quality of decision making - a mediation model. Procedia Computer Science, 64, 1163-1171.

Zeinalova, L. M. (2016). Decision making with combined states under interval uncertainty. Procedia Computer Science, 102, 223-230.

\section{Copyrights}

Copyright for this article is retained by the author(s), with first publication rights granted to the journal.

This is an open-access article distributed under the terms and conditions of the Creative Commons Attribution license (http://creativecommons.org/licenses/by/4.0/). 